\title{
EFEITO DA ADUBAÇÃO NITROGENADA REALIZADA ATRAVÉS DA IRRIGAÇÃO EM UROCHLOA BRIZANTHA CV. MARANDU
}

\author{
Maycon Amim Vieira ${ }^{1}$, Flávio Alberto Oliva ${ }^{2}$ \\ ${ }^{1}$ Universidade Estadual Paulista "Júlio de Mesquita Filho" - UNESP, Mestrado em Ciência e Tecnologia Animal, \\ Dracena, SP. ${ }^{2}$ Universidade do Oeste Paulista - UNOESTE, Presidente Prudente, SP.
}

\section{RESUMO}

Os aspectos ligados à adubação de pastagem, assim como a fertilidade do solo têm sido de grande importância, para a obtenção de um maior desenvolvimento e exploração mais intensiva da pecuária, contribuindo desta forma para o desenvolvimento rural. Esse trabalho tem como objetivo estudar o efeito da adubação nitrogenada realizada através da irrigação em Urochloa brizantha cv. Marandu. O experimento foi realizado em casa de vegetação nas dependências da Escola Técnica Dr. Luiz César Couto em Quatá-SP. Foram analisados a Matéria Verde, Matéria Seca da Haste+Binha, Matéria Seca da Folha e Matéria Seca Total. De acordo com esse estudo, a adubação nitrogenada através da irrigação, pode ser compensatória financeiramente, sendo necessário um estudo econômico-financeiro deste trabalho. Da mesma forma que um estudo com mais cortes para verificar se o resultado econômico-financeiro será compensatório ao longo dos pastejos.

Palavras-Chave: matéria seca, matéria verde, pastagem, produtividade, fertilidade.

\section{EFFECT OF NITROGEN FERTILIZATION PERFORMED THROUGH IRRIGATION IN UROCHLOA BRIZANTHA CV. MARANDU}

\begin{abstract}
Aspects related to fertilization of pasture, as well as soil fertility have been of great importance for the further development and more intensive exploitation of livestock, thus contributing to rural development. This work has as objective to study the effect of nitrogen fertilization performed through irrigation in Urochloa brizantha CV. Marandu. The experiment was conducted in a greenhouse at the technical school Luiz César Couto in Quatá-SP. Were analyzed the Green matter, stem dry matter + Sm, leaf dry matter and Total dry matter. According to this study, the nitrogen fertilizer through irrigation, can be financially rewarding, being necessary a financial study of this work. In the same way that a study with more cuts to check if the result will be compensatory financial over the pastejos.
\end{abstract}

Keywords: Dry matter, green matter, Grassland, productivity, fertility.

\section{INTRODUÇÃO}

Os pastos tropicais são a principal fonte de nutrientes utilizadas para a produção de bovinos no Brasil, sendo que, do rebanho brasileiro de corte, $91 \%$ dos animais abatidos são oriundos dos sistemas baseados em pastagens, nos quais todo o ciclo, desde a cria até a terminação, é realizado sob pastejo (JACOVETTI, 2016). Segundo o mesmo autor, as forragens pastejadas devem ser entendidas como um recurso nutricional de grande importância para a cadeia da carne, leite, lã e outros ruminantes e também um recurso nutricional de elevada complexidade, uma vez que os substratos oriundos da mesma variam qualitativa e 
quantitativamente ao longo do ano e em função dos tipos de cultivares utilizados. Dessa forma, a criação dos animais depende em grande parte da produção de forragem para sua alimentação. A produtividade de um rebanho é comumente prejudicada pelo manejo inadequado da forrageira utilizada, que muitas vezes ocorre devido à falta de conhecimento a respeito de suas características fisiológicas (FISCHER et. al. 2016).

Os aspectos ligados à adubação de pastagem, assim como a fertilidade do solo têm sido de grande importância, para a obtenção de um maior desenvolvimento e exploração mais intensiva da pecuária, contribuindo desta forma para o desenvolvimento rural (VITTI et. al., 2001). O potencial de produção de uma planta forrageira é determinado geneticamente, porém, para que esse potencial seja alcançado, condições adequadas do meio (temperatura, umidade, luminosidade, disponibilidade de nutrientes) e manejo devem ser observados, sendo que, a baixa disponibilidade de nutrientes é, seguramente, um dos principais fatores que interferem na produtividade e na qualidade da forragem (FAGUNDES et. al., 2015).

A pastagem é uma cultura perene, a mesma passa um grande período em um solo, que com o tempo, vai perdendo os nutrientes essenciais aos vegetais, à recomposição dos mesmos passa a ser de fundamental importância, principalmente o nitrogênio, fosforo e potássio (HEINRICHS; FILHO, 2014). Porém, essa necessidade muitas vezes esbarra com dificuldades como mão-de-obra e maquinário, além de outros fatores que geram custo para o produtor, na qual, muitas vezes, torna inviável a pratica de adubação em determinadas propriedades.

Alguns produtores realizam no manejo de pastagem a pratica da irrigação, afim de alcançar o potencial da cultivar. Porém, a irrigação acaba não sendo suficiente em solo deficiente de nitrogênio. Sendo assim, surgi a necessidade de utilizar as duas práticas, mas como utilizar as duas sem aumentar drasticamente o custo de produção? Uma opção pode ser a adubação nitrogenada através da própria irrigação. Mas será que é possível alcançar o mesmo efeito na pastagem realizando a adubação nitrogenada através da irrigação? Afim de responder essa pergunta, esse trabalho tem como objetivo estudar o efeito da adubação nitrogenada realizada através da irrigação em Urochloa brizantha cv. Marandu.

\section{METODOLOGIA}

O experimento foi realizado em casa de vegetação nas dependências da Escola Técnica Dr. Luiz César Couto em Quatá-SP. Foram utilizados 16 vasos de $4 \mathrm{~m}^{3}$, na qual foram preenchidos com solo latossolo de textura média, sendo em seguida realizado a coleta de amostra para a realização da análise de solo, cujo resultado se encontra na tabela 1.

Tabela 1. Resultados da análise de solo.

\begin{tabular}{|c|c|c|c|c|c|c|c|c|c|c|c|}
\hline $\mathrm{pH}$ & M.O. & $P$ & K & $\mathrm{Ca}$ & $\mathrm{Mg}$ & $\mathrm{Al}$ & $\mathrm{H}+\mathrm{Al}$ & SB & $T$ & V\% & $\mathrm{m} \%$ \\
\hline $\mathrm{CaCl}_{2}$ & $\mathrm{~g} / \mathrm{dm}^{3}$ & $\mathrm{mg} / \mathrm{dm}^{3}$ & \multicolumn{7}{|c|}{$\mathrm{mmolc} / \mathrm{dm}^{3}$} & & \\
\hline 5,7 & 5 & 1 & 0,4 & 19 & 6 & 0 & 22 & 25,4 & 47,4 & 54 & 0 \\
\hline
\end{tabular}

No dia 21 de abril, foi realizado a semeadura das sementes de Uruchloa brizantha cv. Marandu em bandeja de muda. No dia 05 de maio, foi realizado a adubação de correção, sendo adicionado $200 \mathrm{mg} \cdot \mathrm{kg}^{-1}$ de $\mathrm{Ca}\left(\mathrm{H}_{2} \mathrm{PO}_{4}\right)_{2} \cdot \mathrm{H}_{2} \mathrm{O}$ como fonte de Fósforo e $150 \mathrm{mg} \cdot \mathrm{kg}^{-1} \mathrm{~K}_{2} \mathrm{SO}_{4}$ como fonte de Potássio em cada vaso, sendo no mesmo dia transplantado as mudas da bandeja, deixando apenas 4 mudas por vaso.

No dia 19 de maio, realizou-se a primeira adubação de cobertura, na qual, os vasos do tratamento 1, recebeu adubação nitrogenada convencional $(2,67 \mathrm{~g}$ de Ureia por vaso), já o tratamento 2 , recebeu adubação nitrogenada através da irrigação $(2,67 \mathrm{~g}$ de Ureia por vaso em 
$62,5 \mathrm{ml}$ de solução por vaso). No dia 02 de junho, foi realizado o primeiro corte a $10 \mathrm{~cm}$ de altura, em seguida a segunda adubação nitrogenada, equivalente a primeira adubação.

As amostras foram levadas para laboratório, onde realizou-se a pesagem de matéria verde (M.V.), em seguida foi realizado a separação morfológica, ou seja, separou-se haste de folhas, sendo levado as mesmas para o Campus de Dracena, da Universidade Estadual Paulista, onde ficou em estufa por 72 horas sob a temperatura de $64{ }^{\circ} \mathrm{C}$ para a realização da secagem, findando as 72 horas realizou-se a pesagem de matéria seca da haste (M.S. (H+B)), matéria seca da folha (M.S. (Folha)) e matéria seca total. (M.S. (Total)).

No dia 23 de junho, foi realizado o segundo corte e realizado o mesmo procedimento do primeiro corte para a identificação de M.V., MS (H+B), M.S. (Folha) e M.S. (Total).

$O$ experimento foi em delineamento inteiramente casualizado, com oito repetição por tratamento. O software utilizado na análise estatística foi o Sisvar (FERREIRA, 2008) na qual realizou-se o Teste de Tukey a nível de 5\% de significância.

\section{RESULTADOS}

As plantas adubadas com nitrogênio líquido (N.L.) apresentaram diferença significativa de matéria verde (M.V.) (Tabela 2) apenas no segundo corte em relação a adubação ao primeiro e em relação a adubação de nitrogênio sólido (N.S.) dos dois cortes. O peso da matéria verde das adubadas com N.L. teve uma diferença de $64 \%$ comparado ao resultado mais inferior dos outros três resultados de M.V.

Tabela 2. Peso de Matéria Verde (M.V.), Matéria Seca da Haste e Bainha (M.S.(H+B)), Matéria Seca da Folha (M.S.(Folha)) e Matéria Seca Total (M.S. Total) de Urochloa brizantha cv. Marandu sob adubação nitrogenada liquida (N.L.) e adubação nitrogenada sólida (N.S.).

\begin{tabular}{ccccc}
\hline & \multicolumn{2}{c}{1 10 Corte } & \multicolumn{2}{c}{2 2o Corte } \\
\cline { 2 - 5 } Tratamento & N.S. & N.L. & N.S. & N.L. \\
\hline M.V. & $8,286 a$ & $7,045 a$ & $7,488 \mathrm{a}$ & $2,492 \mathrm{~b}$ \\
M.S.(H+B) & $0,155 \mathrm{a}$ & $0,090 \mathrm{a}$ & $0,078 \mathrm{a}$ & $0,000 \mathrm{a}$ \\
M.S.(Folha) & $0,740 \mathrm{a}$ & $0,718 \mathrm{a}$ & $0,815 \mathrm{a}$ & $0,228 \mathrm{~b}$ \\
M.S. Total & $0,903 \mathrm{a}$ & $0,817 \mathrm{a}$ & $0,855 \mathrm{a}$ & $0,228 \mathrm{~b}$ \\
\hline
\end{tabular}

Letras iguais não há diferença significativa, letras diferentes há diferença significativa.

A produção de matéria seca da haste e bainha (M.S. $(H+B))$ apresentou melhor resulta no primeiro corte, comparando com o segundo, dentro do primeiro corte, a adubação N.S. apresentou $42 \%$ a mais de matéria seca em relação a da adubação N.L. do mesmo corte. Nessa variável, em nenhum tratamento apresentou diferença significativa.

No primeiro corte, as plantas adubas com N.S., apresentaram diferença de peso de matéria seca de folha (M.S. (folha)) de $3 \%$ em relação a adubação N.L. no mesmo corte, não sendo diferentes estatisticamente. Já no segundo corte apresentaram uma diferença significativa de $72 \%$.

Em relação a matéria seca total (M.S. (Total)), no primeiro corte não houve diferença significativa das duas adubação, porém a adubação N.S. foi superior que a N.L.. Já no segundo corte, a adubação N.S. foi superior significativamente a N.L. em 73\%.

\section{DISCUSSÃO}

De acordo com esse trabalho, pode se dizer que as plantas adubadas com N.L. através da irrigação respondeu bem ao tratamento. Mesmo apresentando resultado inferiores ao da adubação N.S., não apresentaram diferença significativa. Pode-se pensar então que compense utilizar irrigação como ferramenta para a adubação nitrogenada. Segundo trabalho de Restle et. 
Al., (2000) a fonte de nitrogênio não provoca alterações no desempenho animal, ou seja, na produtividade da pastagem.

Pode diluir a ureia na irrigação, para através na mesma, disponibilizar o $\mathrm{N}$ no solo, com isso, o produtor economizaria os custos com hora-maquina, sendo essa produtividade inferior, recompensada na redução de custo. Sendo assim, se tem uma oportunidade de um novo trabalho, tendo como objetivo o estudo da influência da produtividade da adubação N.L. e N.S. nos custos de produção.

O segundo corte apresentou uma queda nos pesos analisados, nos dois tratamentos, com uma diferença mais acentuada na adubação N.L.. A redução de ambos tratamentos pode ser justificada pelo desgaste natural da planta, na qual, vai perdendo o vigor ao logo dos pastejos. Porém, segundo estudos de Alexandrino et al. (2004), a adubação nitrogenada e o tempo de rebrotação são componentes importantes que afetam o crescimento da Brachiaria brizantha cv. Marandu e, por isso, devem ser considerados na determinação de estratégias de manejo da pastagem. Ou seja, a redução da produção no segundo corte pode ser justificada pelo período de rebrotação que não foi suficiente, sendo eles apenas quinze dias.

\section{CONCLUSÃO}

De acordo com esse estudo, a adubação nitrogenada através da irrigação, pode ser compensatória financeiramente, sendo necessário um estudo econômico-financeiro deste trabalho. Da mesma forma que um estudo com mais cortes para verificar se o resultado econômico-financeiro será compensatório ao longo dos pastejos. Como também, um trabalho com intervalo de rebrote mais logo.

\section{AGRADECIMENTOS}

Agradeço aos colaboradores deste trabalho, sendo eles: Ivan Barreto; Lucas Alves; Michel Sevilha da Silva; Renato Lucas de Castro Paião; Renato Oliveira Araújo; e Pablo Rodrigo Oliveira Martins.

\section{REFERÊNCIAS}

ALEXANDRINO, E.; JÚNIOR, D.N.; MOSQUIM, P.R.; REGAZZI; A.J.; ROCHA, F.C. Características Morfogênicas e Estruturais na Rebrotação da Brachiaria brizantha cv. Marandu Submetida a Três Doses de Nitrogênio. Revista Brasileira de Zootecnia. 2004, pag 1372-1379. Acessado em 31 jul 2017. Disponível em: http://www.scielo.br/pdf/rbz/v33n6/a03v33n6

FAGUNDES, J.L.; FONSECA, D.M.; GOMIDE, J.A.; JUNIOR, D.N.; VITOR, C.M.; MORAIS, R.V.; MISTURA, C.; REIS, G.C.; MASTUSCELLO. Acúmulo de Forragem em Pastos de Brachiaria decumbens Adubados com Nitrogênio. Pesquisa Agropecuária Brasileira, Brasília, 2005, p. 397403.

FERREIRA, D. F. SISVAR: um programa para análises e ensino de estatística. Revista Symposium (Lavras), v. 6, p. 36-41, 2008.

FISCHER, T.D.; SULIMAN, N.F.; ZIEGLER, S.J., BUSSLER, A.P.K.; BENETTI, R.; PEREIRA, E.A. Importância das Características Morfofisiológicas na Seleção e Ingestão de Forragem Pelos Animais em Pastejo. Ijuí: UNIJUI. 2016, p. 6.

HEINRICHS, R.; FILHO, C.V.S. Adubação e manejo de pastagens. 1ạ ed. Birigui, SP: Boreal, 2014, p. 180.

JACOVETTI, R. Desempenho Agronômico e Nutricional do Capim “Mulato II" Sob Doses e Fontes de Nitrogênio. Goiânia: UFG, 2016, p. 98. 
RESTLE, J.; ROSO, C.; SOARES, A.B.; LUPATINI, G.C.; FILHO, D.C.A.; BRONDANI, I.L. Produtividade Animal e Retorno Econômico em Pastagem de Aveia Preta mais Azevém Adubada com Fontes de Nitrogênio em Cobertura. Revista Brasileira de Zootecnia, 2000, Pag. 354-364. Acessado em 31 jul 2017, Disponível em: http://s3.amazonaws.com/academia.edu.documents/40538390/5769.pdf? AWSAccessKeyld=AKIAIWOWYYGZ2Y53UL3A\&Expires=1501515663\&Signature=hz2S30ZLNOuQoY n6w21TXFiSD40\%3D\&response-content-disposition=inline\%3B\%20filename\%3DProdutividade animal e retorno economico.pdf

VITTI, G.C; LUZ, P.H.C.; NETO, B.L.C.; SUGIMOTO, L.S. Nutrição e Adubação de Pastagens no Estado de São Paulo. Piracicaba: ESALQ-LSN/FEALQ/GAPE/IAP, 2001, p. 70. 